\title{
Specific behavior of electrolytic copper powders of different morphological forms in temperature fields
}

\author{
T. A. Ovechkina, N. N. Gryzunova ${ }^{\dagger}$, A. A. Vikarchuk, A. M. Gryzunov, A. G. Denisova \\ †'gryzunova-natalja@yandex.ru
}

Togliatti State University, 14 b Belorusskaya St., 445020, Togliatti, Russia

\begin{abstract}
An important goal of materials science is the development of copper powders, which are used as catalysts in reactors based on fluidization bed technology. These reactors are more economical and efficient than the reactors with fixed catalytic layer. However, such reactors put special requirements to the catalysts. The catalyst should be stable in the temperature fields, have high thermal conductivity and wear resistance, certain shapes and sizes of the active particles. Copper powders with approximately the same average particle size, but with different internal structures and surface morphologies were obtained by electrolytic method in this work. A comparative analysis of the results of exposure to temperature fields was also performed. The heating of powders was carried out in a differential scanning calorimeter (X-DSC 7000). Investigations of surface morphology and phase composition changes of the copper powders particles were performed using scanning electron microscopy and X-ray diffraction. It has been shown that particles with different initial structures and morphologies have similar morphological and phase transformations in the process of annealing in air (sintering and loss of particles faceting, the growth of whiskers and oxidation, the formation of cavities inside and pores on the surface). Nevertheless, for the icosahedral small particles of copper, there is an increased release of energy during the heating in DSC, and this energy activates and accelerates structuralphase transformations in the particles. By authors' opinion, this can be related to particular features of the internal structure and morphology of their surface.
\end{abstract}

Keywords: copper, copper powder, icosahedral small particles, thermal treatment, differential scanning calorimetry.

\section{Особенности поведения электролитических медных порошков различных морфологических форм в температурных полях}

\author{
Овечкина Т. А., Грызунова Н.Н. ${ }^{\dagger}$, Викарчук А. А., Грызунов А. М., Денисова А. Г. \\ Тольяттинский государственный университет, ул. Белорусская 14 6, 445020, Тольятти, Россия
}

\begin{abstract}
Важной задачей материаловедения является создание материалов в виде медных порошков, которые могут применяться в качестве катализаторов для реакторов, работающих по технологии псевдоожиженного слоя. Они являются более экономичными и эффективными, чем реакторы с неподвижным слоем катализатора. Однако, такие реакторы предъявляют особые требования к катализатору. Катализаторы должны быть стабильны в температурных полях, обладать высокой теплопроводностью и износостойкостью, иметь определенные формы и размеры активных частиц. В данной работе электролитическим методом были получены медные порошки с примерно одинаковым средним размером частиц, формой близкой к сферической, но разной внутренней структурой и морфологией поверхности. Проведен сравнительный анализ результатов воздействия на них температурных полей. Температурные исследования осуществлялись в дифференциальном сканирующем калориметре (X-DSC 7000). Исследование изменений морфологии поверхности и фазового состава частиц порошков проводилось методами сканирующей электронной микроскопии и рентгеновской дифрактометрии. Показано, что частицы с разной исходной структурой и морфологией поверхности испытывают в процессе отжига на воздухе качественно одинаковые морфологические и фазовые превращения (спекание, потерю огранки, окисление, рост вискеров, образование полостей внутри и пор на поверхности частиц). Но для икосаэдрических малых частиц меди наблюдается повышенное выделение запасенной энергии при нагреве в ДСК, которая активирует и ускоряет протекание структурно-фазовых превращений в них. По мнению авторов, это может быть связано с особенностями внутренней структуры и морфологии поверхности самих икосаэдрических частиц меди.
\end{abstract}

Ключевые слова: медь, порошок медный, икосаэдрические малые частицы, термообработка, дифференциальная сканирующая калориметрия. 


\section{1. Введение}

Одной из важных задач материаловедения является создание функциональных материалов в виде порошков с заданными характеристиками (форма, размер, внутреннее строение, особенности огранки частиц) и свойствами. Такие порошки могут использоваться в качестве катализаторов, сорбентов, наполнителей в композиционных материалах, добавок в лакокрасочные материалы, присадок в топливо и многого другого.

Повышенный интерес представляют частицы медных порошков микронных размеров с формой, близкой к сферической. Именно такие порошки удовлетворяют требованиям, которые предъявляются к катализаторам, работающим в реакторах по технологии псевдоожиженного слоя. Реакторы на основе псевдоожиженного слоя на сегодняшний день являются наиболее перспективными в силу малых габаритов, они экономичны и малоэнергозатратны [1].

Широко распространенным способом получения электролитических медных порошков является способ, описанный в ГОСТ 4960 -2009. Такой порошок состоит из кристаллов сложной дендритной формы и для работы в реакторах с псевдоожиженным слоем не совсем подходит, поскольку кристаллы подвергаются сильному истиранию в процессе их движения. Также методом электроосаждения по различным техническим условиям уже получают частицы сферической формы $[2,3]$ и ультрадисперсных размеров [4-7]. Однако, в силу малых размеров, их использование в реакторах с кипящим слоем создает ряд проблем, таких как быстрый износ, быстрое выгорание, сложности технологии улавливания или извлечения из конечного продукта $[7,8]$. Поэтому правильный выбор интервала рабочих температур катализатора, формы и размера его частиц позволят обеспечить как требуемое качество, так и длительность безрегенерационного пробега и общего срока службы катализатора.

Целью настоящей работы было получение электролитическим способом медных порошков, состоящих из частиц примерно одинакового среднего размера, но с разной исходной структурой и морфологией поверхности и исследование особенностей их поведения в температурных полях.

\section{2. Способы получения и методы исследования}

В данной работе электролитические порошки с различной внутренней структурой и морфологией поверхности получали методом электроосаждения $[9,10]$ из раствора сернокислого электролита следующего состава: $\mathrm{CuSO}_{4}{ }^{*} \mathrm{H}_{2} \mathrm{O}-250$ г/л, $\mathrm{H}_{2} \mathrm{SO}_{4}-98$ г/л, бидистиллят.

Электроосаждение проводили в потенциостатическом режиме в течение 20 минут при перенапряжениях от 80 до 110 мВ в зависимости от того, какую морфологическую форму поверхности частиц порошка необходимо было получить. В качестве подложки использовали нержавеющую сталь марки 12Х18Н10Т. Электроосажденные частицы удалялись с поверхности подложки механически или ультразвуком.
Структуру медных частиц исследовали на просвечивающем микроскопе ПРЭМ-200. Исследование особенностей морфологии поверхности частиц порошков проводили на сканирующем электронном микроскопе Carl Zeiss Sigma. Измерение среднего размера частиц порошка осуществлялось при помощи лазерного анализатора размера частиц Shimadzu SALD-2300. Определение изменения фазового состава частиц порошка в процессе окисления проводилось при помощи рентгеновского дифрактометра SHIMADZU XRD-7000. Нагревание образцов одной массы осуществлялось в дифференциальном сканирующем калориметре (ДСК) X-DSC7000 в атмосфере кислорода от 20 до $700^{\circ} \mathrm{C}$ со скоростью нагрева $10^{\circ} \mathrm{C} /$ мин.

\section{3. Результаты и их обсуждение}

По описанной выше и отработанной нами методике [10] были получены два медных порошка: порошок из ГЦК кристаллов сферической формы (рис. 1а) и порошок из микрочастиц, имеющих пентагональную симметрию в виде икосаэдров (рис. 2a).

Рентгеноструктурные исследования и анализ микрофотографий показали, что первый образец порошка на $100 \%$ состоит из ГЦК кристаллов меди сферической формы (рис. 1a), имеющих средний размер 15-20 мкм. На гистограмме (рис. 1b) показано распределение частиц порошка по размерам. Кристаллы имеют гофрированный рельеф поверхности без четко выраженной огранки (рис. 1a).

Анализ микрофотографий второго порошка показал, что он состоит на $80-90 \%$ из частиц, имеющих пентагональную симметрию, в частности, в виде совершенных и усеченных икосаэдров (рис. 2a). Средний размер таких частиц в порошках (рис. 2b) также составил 15-20 мкм. Ранее проведенные исследования [11-14] структуры и морфологии поверхности икосаэдрических малых частиц (ИМЧ) меди (рис. 2а) показали, что они имеют 12 вершин, 30 ребер, 6 осей симметрии пятого порядка, проходящих через их вершины, содержат частичные дисклинации, в них нарушен дальний порядок, имеется высокая концентрация двойниковых границ, четко выражена текстура и проявляется анизотропия свойств. Совершенные икосаэдрические частицы огранены 20-ю кристаллографическими гранями $\{111\}$, а усеченные икосаэдры огранены 32-ю плоскостями типа $\{111\}$ и $\{110\}$.

Анализ внутреннего строения частиц порошка показал, что сферические частицы меди (рис. 1а) представляют собой поликристаллические агрегаты, состоящие из кристаллов размером 3 - 5 мкм и содержащие в качестве основных дефектов малоугловые дислокационные границы и двойниковые прослойки ростового происхождения (рис. 3a).

В икосаэдрических малых частицах (ИМЧ) основными дефектами строения являются частичные дисклинации, обрывающиеся на них двойниковые границы, двойниковые прослойки и вставки. ИМЧ разделяется двойниковыми границами на 20 секторов, имеющих ГЦК решетку (рис. 2a, 3b). 
Следовательно, сферические медные частицы размером 15-20 мкм представляют собой поликристаллические агрегаты, состоящие из различных кристаллов, выросших в процессе электрокристаллизации из отдельных зародышей и разделенных между собой большеугловыми межзеренными границами. Икосаэдрические частицы меди представляют собой монокристалл, выращенный из одного зародыша, фрагментированного 20-ю двойниковыми границами на сектора с ГЦК решеткой (рис. 3a) $[13,15]$.

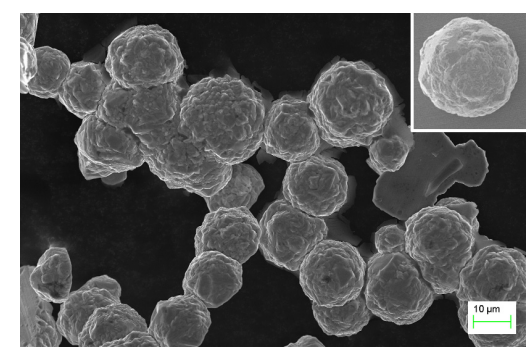

a

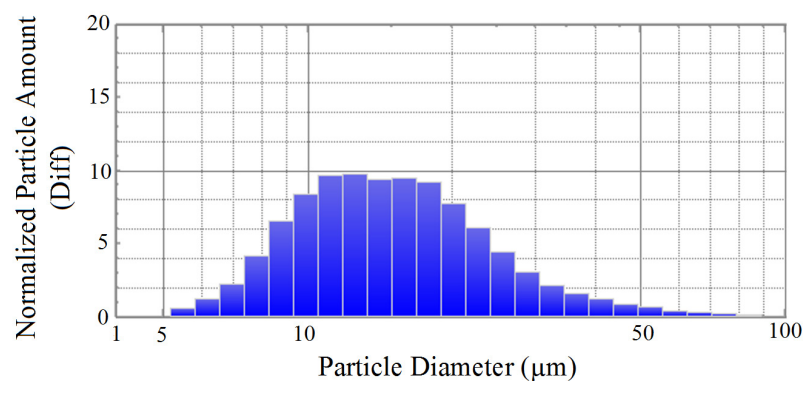

b

Рис. 1. Порошок из ГЦК кристаллов меди сферической формы (образец 1): морфология поверхности (а), распределение по размерам (b).

Fig. 1. Powder of copper FCC crystals of spherical shape (sample 1): the surface morphology (a), size distribution (b).
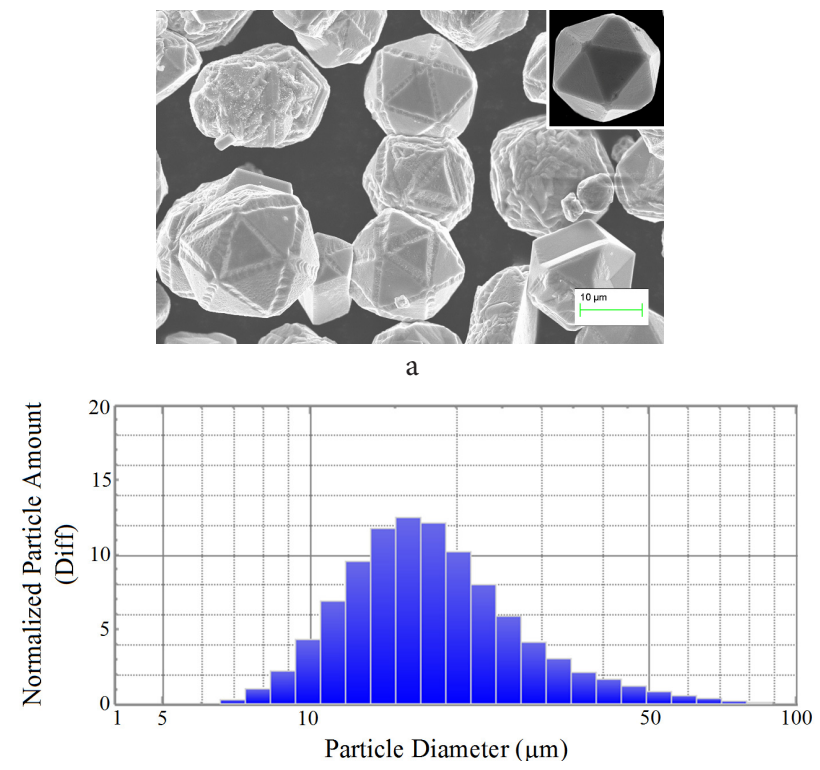

b

Рис. 2. Порошок из икосаэдрических малых частиц меди (образец 2): морфология поверхности (a), распределение по paзмеру (b).

Fig. 2. The powder of the icosahedral small particles of copper (sample 2): the surface morphology (a), size distribution (b).
Таким образом, проведенный анализ морфологии поверхности, внутренней структуры и гистограммы распределения по размерам частиц порошков показали, что при одинаковом среднем размере, частицы порошков имеют существенные различия не только в морфологии поверхности, но и во внутренней структуре, что, по нашему мнению, должно сказываться на их поведении в температурных полях.

Действительно, калориметрические исследования показали существенные различия в полученных термограммах (рис. 4). Однако, фазовый состав частиц в процессе окисления изменялся качественно одинаковым образом, что фиксировалось с помощью рентгеновского дифрактометра: медь в процессе нагрева поэтапно превращалась в оксиды $\mathrm{Cu}_{2} \mathrm{O}$ и $\mathrm{CuO}$.

На графиках ДСК обоих порошков (отличающихся друг от друга исходной структурой и морфологией поверхности), наблюдался первый экзотермический пик

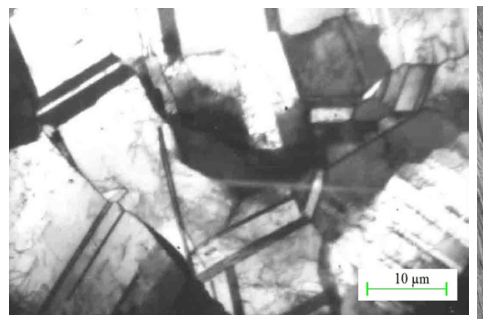

a

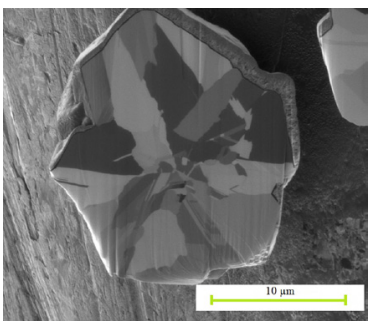

b
Рис. 3. Микрофотографии электроосажденных частиц меди: частицы с ГЦК решеткой (a), икосаэдрические малые частицы (b).

Fig. 3. Micrographs of electrodeposited copper particles: particles with the FCC lattice (a), icosahedral small particles (b).
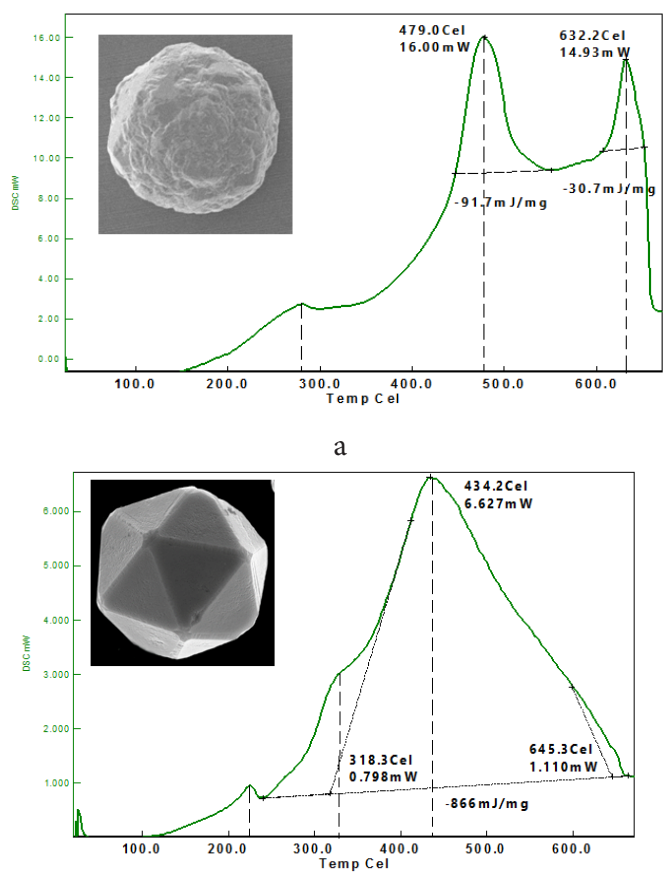

$\mathrm{b}$

Рис. 4. Графики изменения теплового потока в зависимости от структуры и морфологии поверхности частиц: образец 1 (a), образец 2 (b).

Fig.4. The graphs of the variation of heat flow depending on the structure and surface morphology of particles: sample 1 (a), sample 2 (b). 
в интервале температур $200-300^{\circ} \mathrm{C}$. Согласно микроскопическим исследованиям, этот пик можно связать с процессом спекания частиц меди (рис. 5). Причем замечено, что спекание ИМЧ меди происходит при более низких температурах (порядка $210-230^{\circ} \mathrm{C}$ ) и более интенсивно, чем для обычных медных частиц, состоящих из ГЦК кристаллов (рис. 4).

Далее, на термограмме первого порошка наблюдаются два ярко выраженных экзотермических пика при температурах примерно 480 и $630^{\circ} \mathrm{C}$ (рис. 4a), а на термограмме ИМЧ - только один большой пик в интервале $300-600^{\circ} \mathrm{C}$ (рис. 4b). Пики тепловыделения при температуре около $450-480^{\circ} \mathrm{C}$, вероятно, связаны с различными процессами, протекающими внутри и на поверхности частиц, в частности, с окислением, рекристаллизацией, упорядочиванием дислокационных образований, образованием вискеров и др.

Исследования особенностей изменения строения и морфологии поверхности обычных частиц и ИМЧ меди в температурных полях показали, что для тех и других, уже при температуре $400^{\circ} \mathrm{C}$, кроме образования на их поверхности массива вискеров, внутри частиц начинает образовываться полость (рис. 6с), что согласуется с работами других авторов [15-17]. Однако, интенсивность роста вискеров, их количество, а также скорость формирования и размер внутренней полости в ИМЧ меди существенно выше, чем у обычных частиц [18].

Следующий экзотермический пик при $630^{\circ} \mathrm{C}$ для образца 1 может быть связан с дальнейшими релаксационными процессами, которые включают исчезновение вискеров и образование нанопор на поверхности частиц, концентрация которых может достигать $10^{10} \mathrm{~cm}^{-2}[19,20]$, а также дальнейшее формирование в них больших внутренних полостей (рис. 7a).

Для порошка из ИМЧ (образец 2) наблюдается объединение двух экзотермических пиков в один (рис. 4b). При этом частицы также окисляются, на их поверхности образуются поры, а внутри открытые или закрытые большие полости [19-20] (рис. 6c, 7b). Однако из графиков видно, что изменение энтальпии для порошка из ИМЧ в 9 раз больше, чем для порошка из сферических ГЦК кристаллов (рис. 4а). По нашему мнению, это связано с тем, что ИМЧ обладают большой запасенной внутренней энергией в виде высокоэнергетических дефектов дисклинационного типа $[11,12,20]$. Запасенная в объеме ИМЧ в процессе электрокристаллизации упругая энергия, под воздействием температурных полей трансформируется в поверхностную энергию, что способствует интенсификации морфологических и структурных превращений и снижает температуры, при которых они реализуются.

\section{4. Заключение}

Таким образом, в работе были получены два медных порошка из обычных и икосаэдрических частиц, которые имеют сферическую форму и примерно одинаковый средний размер частиц, но разную исходную структуру и морфологию поверхности.

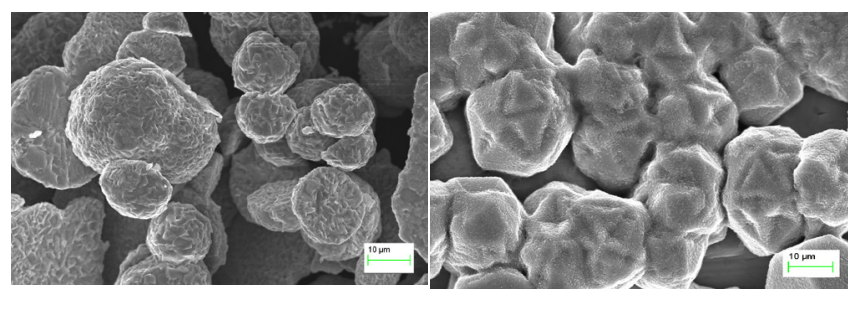

a

b

Рис. 5. Частицы медных порошков после нагрева до $200^{\circ} \mathrm{C}$ : образец 1 (a), образец 2 (b).

Fig. 5. Particles of copper powders after heating to $200^{\circ} \mathrm{C}$ : sample 1 (a), sample 2 (b).
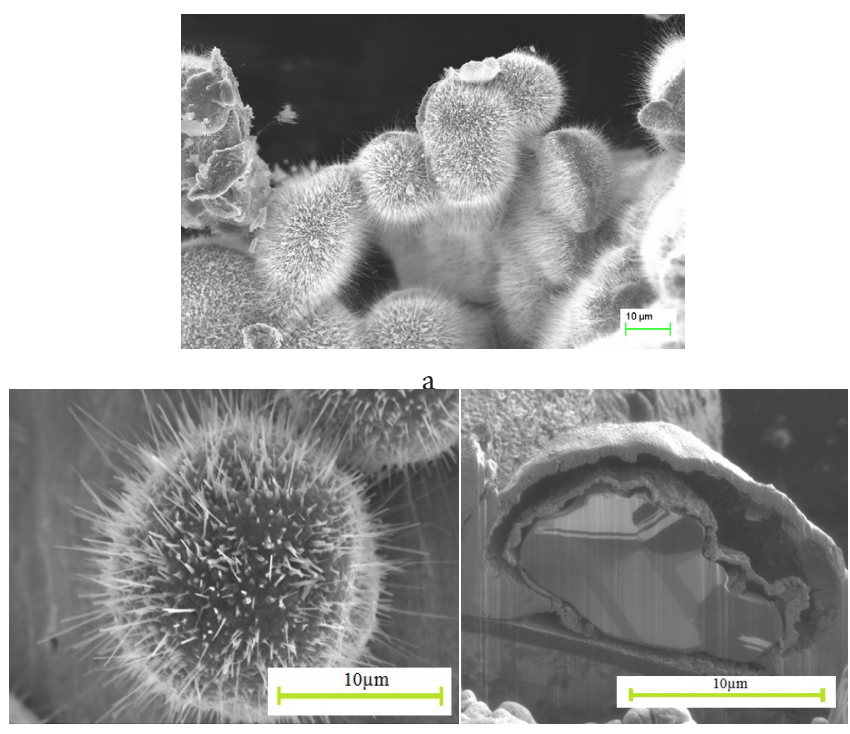

$\mathrm{b}$

$\mathrm{c}$

Рис. 6. СЭМ изображение морфологии поверхности частиц порошка меди после отжига при $T=400^{\circ} \mathrm{C}$ : образец 1 (a), образец 2 (b), ИМЧ меди после отжига в разрезе (c).

Fig. 6. SEM image of surface morphology of powder particles of copper after annealing at $T=400^{\circ} \mathrm{C}$ : sample 1 (a), sample 2 (b), ISP of copper after annealing in a cross section (c).

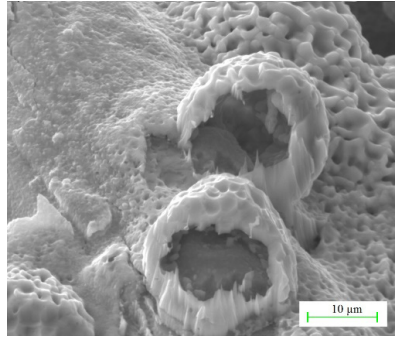

a

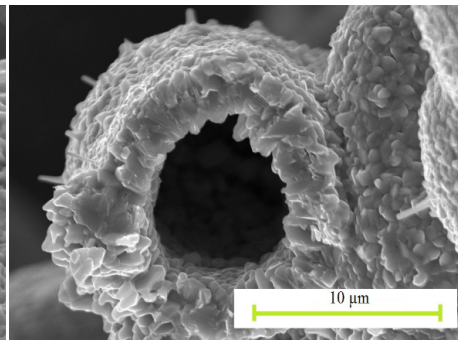

$\mathrm{b}$
Рис. 7. СЭМ изображение морфологии поверхности частиц порошка меди после термообработки при $T=600^{\circ} \mathrm{C}$ : образец 1 (a), образец 2 (b).

Fig. 7. SEM image of surface morphology of powder particles of copper after heat treatment at $T=600^{\circ} \mathrm{C}$ : sample 1 (a), sample 2 (b).

В температурном поле и воздушной атмосфеpe в медных частицах любой морфологии наблюдаются следующие изменения: в интервале температур $200-300^{\circ} \mathrm{C}$ начинается спекание частиц, в температурном интервале $350-450^{\circ} \mathrm{C}$ на поверхности частиц растут вискеры, а при температуре $400-700^{\circ} \mathrm{C}$ на поверхности частиц формируются нанопоры, внутри них образуют- 
ся полости, окруженные слоистой оболочкой из оксидов меди. При этом структурно-фазовые превращения сопровождаются выделением теплоты и морфологическими изменениями частиц. Однако интенсивность процессов спекания, роста вискеров, формирования пор на поверхности и полости внутри у частиц икосаэдрической формы, обладающих пентагональной симметрией, значительно выше. Это связано с особенностями строения ИМЧ, а именно, содержащимися в них высокоэнергетическими дефектами дисклинационного типа, которые обладают большой запасенной упругой энергией, что приводит к структурно-фазовым изменениям при более низких температурах отжига.

Благодарность/Acknowledgements. Исследование выполнено при финансовой поддержке РФФИ в рамках научного проекта № 16-02-00517 $a$. The reported study was funded by RFBR according to the research project № 16-02-00517 $a$.

\section{Литература/References}

1. J. Diduszycki. Principles of design of catalytic reactors. Chemistry. (1972) 376p. (in Russia) [Я. Дидушинский Основы проектирования каталитических реакторов. Химия. 1972. 376с.]

2. V.P. Dmitrienko, O. I. Nalesnik. Electrochemical method of producing copper powder. Study guide. Tomsk, NITPU (2013) 19p. (in Russia) [В.П. Дмитриенко, О.И. Налесник Электрохимический способ получения медного порошка. Учебное пособие. Томск, НИТПУ. 2013. 19с.]

3. M.S. Kapitsa, N.P. Ivanova. Applied electrochemistry. Study guide. Minsk, BSTU (2006) 56p. (in Russia) [M. С. Капица, Н. П. Иванова.Прикладная электрохимия. Учебное пособие. Минск, БГТУ. 2006. 56с.]

4. V.M. Maksimovic, Lj.J. Pavlovic, M.G. Pavlovic, M.V. Tomic. Characterization of copper powder particles obtained by electrodeposition as function of different current densities // Journal of Applied Electrochemistry 39 (12), (2009). p. 2545-2552, DOI: 10.1007/s10800-009-9950-y

5. H. Hashemipour, M.E. Zadeh, R. Pourakbari, P. Rahimi Investigation on synthesis and size control of copper nanoparticle via electrochemical and chemical reduction method // International Journal of the Physical Sciences.6, (2011).p. 4331 - 4336.

6. M. V. Tesakova, V.I. Parfenyuk. Surface Engineering and Applied Electrochemistry. 46 (5), (2010). p. 400 -405. (in Russia) [М. В. Тесакова, В.И. Парфенюк. Электронная обработка материалов. 5 (2010). С. 11 - 16.]

7. Yu. M. Berezhnoy. Obtaining of ultradispersed powders of copper, stable water-soluble polymers, antifriction metal-polymer materials: Dissertacija na soiskanie stepeni kandidata tehnicheskih nauk. Novocherkassk. (2015) 134p. (in Russia) [Ю.М. Бережной. Получение ультрадисперсных порошков меди, стабилизированных водорастворимыми полимерами, для антифрикционных металло-полимерных материалов: дис. канд. тех. наук. Новочеркасск. 2015. 134c.]

8. A.I. Kozlov, V.L. Zbarsky. Russian Journal of General Chemistry. 3 (2006) Р. 131 - 139. (in Russia) [А. И. Козлов, В.Л. Збарский. Российский химический журнал. 3 (2006) C. 131 - 139.]

9. T.A. Ovechkina, N.N. Gryzunova, A.A. Vikarchuk. Scientific Bulletin. 1 (7), (2016). P. 168 - 173. (in Russia) [Т.А. Овечкина, Н.Н. Грызунова, А.А. Викарчук. Научный вестник. 1 (7), (2016). C. 168 -173.] DOI: $10.17117 / \mathrm{nv} .2016 .01 .168$

10. N.N. Gryzunova, A.G. Denisova, I.S. Yasnikov, A.A. Vikarchuk. Russian Journal of Electrochemistry. 51 (12). (2015) P. 1176-1179. DOI: 10.1134/S102319351512006X.

11. I.S. Yasnikov, A.A. Vikarchuk. Bulletin of the Russian Academy of Sciences: Physics. 69 (9). (2005). P. 1548 - 1553. (in Russia) [И. С. Ясников, А. А. Викарчук. Известия российской академии наук. Серия физическая. 69 (9). (2005). С. 1378 - 1382.]

12. I.S. Yasnikov, A.A. Vikarchuk. Technical Physics Letters. 19 (2007). Р. 24 - 31. (in Russia) [И.С. Ясников, A. А. Викарчук. Письма в Журнал технической физики.19 (2007). С. 24 - 31.]

13. I.S. Yasnikov, A.A. Vikarchuk. Metal Science and Heat Treatment. 3 (2007). Р. 13 - 16. (in Russia) [И. С. Ясников, А. А. Викарчук. Металловедение и термическая обработка материалов. 3 (2007). С. 13 - 16.]

14. C. J. Love, J. D. Smith, Y. Cui, K. K. Varanasi. Nanoscale. 3 (2011). P. 4972.

15. A.A. Vikarchuk, N.N. Gryzunova, D.A. Denisova [et al.]. Journal of functional materials. 5 (2008). P. 163 - 174. (in Russia) [А. А. Викарчук, Н.Н. Грызунова, Д.А. Денисова [и др.]. Журнал функциональных материалов. 5 (2008). С. 163 - 174.]

16. U. Nerle, M. K. Rabinal. IOSR Journal of Applied Physics. 5 (2013). P. $01-07$.

17. M. Perez-Tello, H.Y. Sohn, J. Lottiger. Minerals \& metallurgical processing. 16 (2). (1999). P. $1-7$.

18. Yasnikov I. S.,Vikarchuk A. A. Technical Physics Letters. 32 (10). (2006). P. $825-826$.

19. A. A. Vikarchuk, E. Yu. Vlasenkova, N. N. Gryzunova. Proceedings of the Samara scientific center Russian Academy of Sciences. S6 (2008). P. 44-49. (in Russia) [А.А. Викарчук, Е. Ю. Власенкова, Н.Н. Грызунова. Известия Самарского научного центра Российской академии наук.S6 (2008). C. 44 - 49.]

20. Gryzunova N.N., Vikarchuk A.A., Bekin V.V., Romanov A.E. Bulletin of the Russian Academy of Sciences: Physics. 79 (9). (2015). P. 1093-1097. (in Russia) [Н.Н. Грызунова, А. А. Викарчук, В. В. Бекин, A.Е. Романов // Известия Российской академии наук. Серия физическая, 2015, том 79, № 9, С. 1238-1243] 